\title{
Memória discursiva e a Análise do Discurso na perspectiva pecheuxtiana e sua relação com a memória social
}

\author{
Cássio Michel dos Santos Camargo
}

\begin{abstract}
Resumo: O presente artigo tem o intuito de tecer reflexões introdutórias sobre os conceitos de Análise de Discurso de linha francesa, baseada nos escritos de Michel Pêcheux, em especial, sobre a memória discursiva. Este artigo foi desenvolvido durante a pesquisa de mestrado no PPGEDU da UFRGS. Para construir essas reflexões, que teve início uma pesquisa de cunho bibliográfico, na qual foram revisitados os principais textos de Pêcheux para mapear a construção dos conceitos da Análise do Discurso, com foco no conceito de memória discursiva. Assim, este artigo estruturou-se com base em três etapas: a primeira delas busca entender o contexto histórico da construção intelectual de Pêcheux; a segunda vislumbrou refletir sobre as bases teórico-metodológicas da Análise Discursiva e a terceira etapa do artigo refletiu sobre o conceito de memória discursiva, análise do discurso e a sua relação com a memória.
\end{abstract}

Palavra-chave: Memória; Memória Discursiva; Análise do Discurso.

Discursive memory in the Discourse Analysis in the pecheuxtian perspective and its relationship with the social memory

\begin{abstract}
This article intends to make some introductory reflections on the concepts of French line Discourse Analysis, based on the writings of Michel Pêcheux, especially on the concept of discursive memory. This article was developed during the master's research in the PPGEDU of UFRGS. To construct these reflections, we carried out a bibliographical research, in which we review the main texts of Pêcheux to map the construction of the concepts of Discourse Analysis, focusing on the concept of discursive memory. Thus, this article was structured based on three stages: the first one seeks to understand the historical context of the intellectual construction of Pêcheux; the second stage saw a reflection on the theoretical and methodological bases of Discursive Analysis and the third stage of this article reflected on the concept of discursive memory and discourse analysis.
\end{abstract}

Keywords: Memory; Discursive Memory; Discourse Analysis.

Memoria discursiva y Análisis del Discurso en la perspectiva pecheuxtiana y su relación con la memoria social

Resumen: Este artículo pretende proporcionar reflexiones introductorias sobre los conceptos de Análisis del Discurso de línea francesa, basado en los escritos de Michel Pêcheux, especialmente sobre la memoria discursiva. Este artículo fue desarrollado durante la investigación del máster en el PPGEDU de la UFRGS. Para construir estas reflexiones, se comenzó una investigación bibliográfica, en la que se revisaron los textos principales de Pêcheux para trazar un mapa de la construcción de los conceptos del Análisis del Discurso, centrándose en el concepto de la memoria discursiva. Así, este artículo se estructuró en tres etapas: la primera busca comprender el contexto histórico de la construcción intelectual de Pêcheux; la segunda vislumbró una reflexión sobre las bases teórico-metodológicas del Análisis Discursivo y la tercera etapa de este artículo reflexionó sobre el concepto de memoria discursiva, análisis del discurso y su relación con la memoria.

Palabra clave: Memoria, Memoria discursiva y Análisis del discurso.

\section{Introdução}

“ut nihil non iisdem verbis redderetur auditum" ", (BORGES, 2000, p. 77).

\footnotetext{
${ }^{1}$ Em tradução livre: nada que foi ouvido pode ser dito outra vez com as mesmas palavras.
} 
A escolha da epígrafe do trecho final da obra "Naturalis Historia" de Plínio cita por Borges (2000), em seu famoso conto "Funes, o Memorioso", e está ligada à memória fenomenal do personagem que dá nome ao conto, o qual devido a um acidente tornou-se incapaz de esquecer, entretanto, esse excesso de memória é impeditivo, pois, para lembrar um dia, perde outro, devido a sua condição singular, o personagem de Borges não constrói a ilusão de ser origem do discurso, já que a sua vida tornou-se uma prisão cercada pela presença excessiva da lembrança. Assim, a citação que escolhemos evoca a impossibilidade de um novo enunciador, em condições de normalidade, repetir o que já foi expresso por outrem. $\mathrm{O}$ cenário citado constitui-se pelo simples fato que todos nós esquecemos, tal ato de esquecer é fundador da nossa condição de sujeito. Sem tal ilusão, o “eu”, a nossa existência seria uma simples alegoria para a existência de "nós" supremo, absoluto e simbiótico com tempo. Desse modo, no anseio de compreender os processos que condicionam a Análise do Discurso e a Memória Discursiva, organizamos o presente artigo, tal esforço intelectual é fruto de algumas demandas de pesquisa do período de estudos de Mestrado em Educação.

Este artigo foi pensado como uma revisão de cunho bibliográfico, nesse esforço de pesquisa, analisamos os principais textos de Pêcheux para mapear a construção dos conceitos que formaram a sua compreensão de Análise do Discurso, com foco na relação proposta pelo autor entre o Discurso e a Memória Discursiva. Para elaborar essa análise, produzimos três etapas analíticas que foram aplicadas ao conjunto de textos de Pêcheux. Inicialmente, queríamos entender o contexto histórico da construção intelectual de Pêcheux e as bases teórico-metodológicas da sua Análise de Discurso, outro desafio de compreensão dessa teoria foi entender a relação entre o Conceito de Memória Discursiva e Discurso na obra desse autor.

As etapas analíticas que nortearam e que foram base para a exposição e a organização deste texto representam uma das muitas possibilidades de pesquisa existentes na obra de Pêcheux. Os resultados apresentados neste artigo têm como objetivo central facilitar o acesso a pesquisadores iniciantes a alguns conceitos chaves do autor, como é o caso do conceito de Memória Discursiva. Entretanto, os desafios da apropriação desses conceitos expostos no texto não se esgotam nessa breve pesquisa.

\section{Fundamentação Teórica}

\subsection{A definição de Análise do Discurso e seu percurso histórico}


Michel de Pêcheux foi fundador da Escola Francesa de Análise do Discurso Crítica. Para Fairclough (2008), foi Pêcheux o responsável pelo desenvolvimento da Análise Crítica do Discurso, com as suas pesquisas fortemente influenciadas pelo contexto político francês. As reflexões de Pêcheux tiveram, como base inicial, as teses de Althusser, o qual estabeleceu intersecções entre a Linguagem, a Ideologia e as Ciências Humanas a fim de compreender a materialidade histórica da língua, que, segundo o seu pensamento, faz-se pelo discurso. É importante destacar que o pensamento desse autor não desenvolveu uma teoria fixa a posturas e doutrinas, pois ele recriou, durante todo o seu percurso intelectual, várias vezes, a Análise do Discurso (AD).

Para Fairclough (2008), mesmo que Pêcheux tenha se aproximado das teorias já desenvolvidas por Althusser e outros autores de destaque da área, ele fez também leituras próprias, direcionadas para formar as teorias usadas pela AD. Dentro da teoria althusseriana, formatou os seus estudos sobre a ideologia que, para ele, é a materialidade do discurso. É sob a responsabilidade da ação ideológica que o sujeito é interpelado, devendo assumir a sua posição de sujeito social. Essa postura ocorre dentro das instituições sociais (denominadas, por Althusser, como Aparelhos Ideológicos do Estado) (2008). O grande avanço da teoria pecheuxtiana consiste na compreensão do discurso como materialidade ideológica, que se apresenta no discurso. "[...] O termo discurso é usado para enfatizar a natureza ideológica do uso da linguística” (FAIRCLOUGH, 2008, p. 54).

$\mathrm{Na}$ teoria do discurso pecheuxtiana, o discurso é percebido como opacidade. Segundo Orlandi (2005, p. 10), Pêcheux "concebe o discurso como um lugar particular em que esta relação ocorre e, pela análise do funcionamento discursivo, ele objetiva explicitar os mecanismos de determinação história dos processos de significação. Estabelece como central entre o simbólico e o político". A proposta de análise de discurso construída por Pêcheux lançou questionamentos sobre a linguagem, que, até então, não era pensada como parte de um mecanismo ideológico. Assim, Pêcheux refletiu sobre o uso realizado pelas Ciências Sociais, que se apropriavam da linguagem sem considerar os desejos políticos impressos língua. Nas formulações de Pêcheux, o discurso passa a ser tratado com a materialização da linguagem (ORLANDI, 2005). Esse autor começa a criticar a noção do sujeito do discurso, produtor de sentido, deixando clara a ilusão que todo o sujeito é ser origem do discurso e dos seus sentidos. O Campo Discursivo, para Michel de Pêcheux, é construído a partir de seis conceitos: história, sujeito, língua, ideologia, sentido e discurso, propriamente dito. Nessa perspectiva, a linguagem representa a materialização do discurso dentro de uma exterioridade, que é social. Nesta, cada sujeito está ocupado de uma posição não fixada, mas determinada pela sua inscrição ideológica. 
Para Orlandi (2005), a Análise do Discurso se estabelece como uma disciplina de entremeios, que faz a intersecção entre as Ciências Humanas e a Linguística. A língua passa a construir os seus múltiplos sentidos, que só pode ser interpretada e ser "entendida" quando vista pela sua historicidade. Essa historicidade pode usada para pensar a própria $A D$, que surgiu na França na década de 1960, tendo em vista que essa vertente teórico-metodológica buscou opor-se à Análise de Conteúdos, que estava em voga nas Ciências Humanas. Essa nova via percebe o texto com um sentido transparente e dado, assim sendo, para a AD, o discurso é um local imbricado e nebuloso, que deve ser analisado e interpretado.

As posições interpretativas assumidas pelos sujeitos devem levá-los a ver os discursos a partir "do modo de funcionamento linguístico-textual [desses], [considerando] as diferentes modalidades do exercício da língua num determinado contexto histórico-social de produção" (BRANDÃO, 1998, p. 19). A vertente francesa da Análise do Discurso, segundo Narzetti (2010), tem três caminhos teóricos: o de Michel Pêcheux; o da Sociolinguística (de Marcellesi, Gardin e Guespin) e de Michel Foucault. Logo, podemos perceber que o projeto da $\mathrm{AD}$ francesa não se fez em um campo de estudo homogêneo, uma vez que as construções teóricas pecheuxtianas e as suas reconstruções tiveram como base as relações teóricometodológicas da Linguística e do materialismo histórico e, a partir dessas, foi cunhado o seu conceito de discurso.

\subsection{Pêcheux e a análise do discurso: seus conceitos e caixa de ferramentas}

Na obra "Por uma Análise Automática do Discurso: Introdução a obra de Pêcheux", Paul Henry (1997) afirma que Pêcheux construiu as suas bases intelectuais nos anos de 1960, no auge do estruturalismo. Assim, no estruturalismo, o autor busca construir uma ideia não reducionista acerca da linguagem. Portanto, Pêcheux deseja instrumentalizar as Ciências Sociais, para isso, ele:

Concebeu sua análise automática do discurso como um instrumento, este não era de nenhum modo análogo aos que ele via utilizados nas ciências sociais. Mas ele não se limitava a recusar esta utilização (empírica) dos instrumentos; ele procurou depreender aquilo que tornou possível esta utilização, e que fez com que ela se tornasse dominante no campo preenchido pelas ciências sociais. Neste ponto, sua critica ao modo de se servir dos instrumentos nas ciências sociais confunde-se com sua crítica as ciências sociais em si mesmas, uma crítica que diz respeito à ligação dessas ciências com o político (HENRY, 1997, p. 20).

A ligação entre as Ciências Sociais e a Política, pautada pela ideologia, inscreve-se, para Pêcheux, na linguagem. Dentro dessa perspectiva teórica, a ideologia faz-se representar pela linguagem e essa pressuposição compreende que a linguagem não pode ser reduzida a 
um mero recurso comunicativo, mas deve ser vista como um mecanismo de imposição ideológica. A ruptura proposta por Pêcheux considera a linguagem no seu sentido político e ideológico como discurso (referência).

Em sua obra "Análise Automática do Discurso (ADD-69)", Pêcheux (1997) estabelece o desejo de construir uma ferramenta de análise para as Ciências Sociais. Para estabelecer essa crítica, Henry (2005, p. 17) aponta para o ataque de Pêcheux à reprodução indiscriminada dos métodos científicos. Para ele, essas utilizações emperram a construção dos métodos dentro das Ciências, o desejo de verdade ou de veracidade estaria apenas legitimado pelo método e não pelas reflexões apontadas nos estudos.

Pêcheux (1997) buscou discutir os conceitos de língua e fala, usando as teses de Saussure, que compreende a língua como um fato social externo aos indivíduos e a fala, como algo individualizado. Segundo Pêcheux, na compreensão de Saussure, "a língua é um sistema de significados, que não deseja estabelecer sentidos, essa negação possibilita que ela torne-se objeto da ciência" (1997 [1969], p. 62.). Essa posição leva-nos a pensar a língua historicizada, fruto de tensões e herdeira de vestígios do que já foi fala, mas que se transmutou em língua. Segundo Queiroz (2003, p. 3), a língua

\begin{abstract}
se caracteriza como estrutura sendo que o que se opõe a essa estrutura é o acontecimento que se define historicamente e o sujeito é um efeito dessa relação da estrutura com o acontecimento. No que diz respeito ao funcionamento da língua, este não é somente linguístico, mas também está e relação à colocação dos protagonistas no discurso, isto é, as condições de produção, pois para Pêcheux era importante explicitar o funcionamento dos processos discursivos na sociedade, por isso a centralidade desta noção.
\end{abstract}

Para Pêcheux, a língua e a "história" relacionam-se construindo um entremeio que é o discurso. Neste sentido, segundo Queiroz, "a língua funciona como base material que atua na compreensão dos seus sentidos, que são construídos na história (através do sujeito e no sujeito), produzindo efeitos de sentido" (2003, p. 4). Com isso, podemos afirmar que o discurso se caracterizaria por uma singularidade. Porque, para Pêcheux, o discurso rompe com a Linguística, estando no entremeio. Já que discurso é:

[...] uma parte de um mecanismo em funcionamento, isto é, como pertencente a um sistema de normas nem puramente individuais nem globalmente universais, mas que derivam da estrutura de uma ideologia política, correspondendo, pois, a um certo lugar no interior de uma formação social dada (PÊCHEUX, 1997 [1969], pp. 76-7).

De acordo com Queiroz (2003, p. 2), na sua obra AAD, Pêcheux objetivou desenvolver um "dispositivo teórico-analítico, a qual estabelece uma crítica às análises simplificadoras utilizadas no período para pensar a língua e que reduzia a mesma ao conteúdo e a informação, sem refletir sobre as suas funções político-ideológicas”. Podemos pensar as 
construções intelectuais de Pêcheux dentro do momento da ruptura dos paradigmas das ciências humanas ${ }^{2}$, já que era impossível pensar a língua fora das disputas ideológicas. Assim, a Análise de Discurso pecheuxtiana se estabelece a partir da definição de discurso, que não pode ser entendido apenas por elementos linguísticos, mas por fatores extralinguísticos e, um deles, é a ideologia que tem a sua ligação direta.

Essa composição extralinguística se estabelece pelas Formações Discursivas, que se definem como "um conjunto complexo de atitudes e representações que não são individuais nem universais, mas se relacionam mais ou menos diretamente a posições de classes em conflito umas com as outras" (HAROCHE; HENRY; PÊCHEUX, 2007, p. 26.). Logo, há uma relação direta entre as formações ideológicas e as formações discursivas. As formações ideológicas aparecem como marcadores constantes nos discursos, porque permitem que os sujeitos inscrevam-se dentro das formações discursivas, que acabam por determinar as possíveis posições do sujeito.

Os discursos são formados na convergência e não podem ser vistos fora dos seus contextos sócio-históricos de produção. Logo, o contexto histórico é formador de sentido e de significado. As condições de produção representam o contexto em que ocorre a enunciação de um discurso (HAROCHE, HENRY E PÊCHEUX, 1997) O discurso é impregnado pelo seu contexto de produção, trazendo em si o sujeito, os seus sentidos e as formações discursivas que lhe constituíram.

O discurso tem a língua como o seu objeto, porém ele não se desvincula da sua materialidade (a ideologia). Dentro dessa materialidade, os sujeitos assumem várias posições de classe. A AD vislumbra questões teóricas sobre o percurso que o sujeito realiza durante o discurso, buscando compreender os sentidos, que lhe são atribuídos conforme a sua inscrição ideológica, que não está desconectada da sua historicidade. Percebemos, assim, que os efeitos de sentido transbordam o domínio da Linguística, no qual a materialidade do discurso não seria notada, pois, os conceitos de Pêcheux inscrevem-se para além dos domínios da linguagem. Na sua Obra semântica e discursos, Pêcheux trata da quebra de alguns vínculos teóricos, a Linguística:

os termos: interdiscurso, intradiscurso, efeito de pré-construído e efeito-transverso introduzidos ao longo deste trabalho e que justamente caracterizam, segundo o que pensamos, a forma da discursividade - não correspondem, portanto, a fenômenos linguísticos: representam, em relação à base linguística, a existência determinante do todo complexo das formações ideológicas, submetido, em condições históricas sempre específicas, à lei "geral" de desigualdade que afeta essas formações (enquanto ideologias práticas e ideologias teóricas, e através de suas características

\footnotetext{
${ }^{2}$ Novas fontes, novos métodos e percepção que a construção dos paradigmas das Ciências Humanas está baseado em representações e não em verdades como propuseram os métodos positivistas até então em voga. Referência.
} 
ao mesmo tempo "regionais" e de classe) no processo de reprodução/transformação das relações de produção existentes (1988, p. 259).

Retomando a primeira obra de Pêcheux, Análise Automática do Discurso, Ferreira (1996) afirmou que a "caixa de ferramentas" analítica desse autor teve a sua formação inicial na apropriação de conceitos de outras áreas de conhecimento, que foram incorporados durante o percurso intelectual de Pêcheux. Dentre esses conceitos, Ferreira (1996) destaca o de História, de língua, de ideologia, de sujeito e de discurso. No contexto da $\mathrm{AD}$, o conceito de História desvincula-se do lado histórico, para buscar o sentido, exposto pela historicidade da língua; a História dá significado ao discurso. Assim, a ideologia na teoria da Análise de Discurso pecheuxtiana ganha importância, pois, através dela, a língua ganha sentido histórico, constituindo o sujeito e o sentido do discurso que acredita ser origem. Quando pensamos em sujeito, Ferreira afirma que:

os processos discursivos vão se desenvolver pelo sujeito, mas não têm nele sua origem. Isto se deve ao descentramento da noção no âmbito discursivo, o que a faz distanciar-se do sujeito consciente, senhor de seus atos e com controle sobre a língua. O sujeito do discurso, em sua relação com a língua, estabelece um processo de constituição mútua, constituindo-se e constituindo-a no seio de acontecimentos histórico-sociais. Assim, ele não é totalmente livre, dado o modo de sua constituição, nem totalmente determinado por mecanismos externos (1996, p. 191).

O sujeito da AD é portador da certeza de ser origem do discurso. Nesse âmbito, o conceito de sentido é fruto do coletivo. Logo, ele é formado por uma rede de memória. Essa condição dá-lhe uma noção de naturalidade, que esconde a opacidade das suas manifestações. Para Ferreira (1996, p. 194), "a teoria do discurso é também uma teoria da materialidade do sentido, que procura dar conta da ilusão necessária do sujeito - senhor da língua e fonte de seu dizer". Para fecharmos a lista de utensílios da caixa de ferramentas da $\mathrm{AD}$, lançamos mão novamente das palavras de Ferreira:

O discurso é o objeto que nos permite observar as relações entre ideologia e língua, bem como os efeitos do jogo da língua na história e os efeitos desta na língua. É através do discurso que se vai compreender como um material simbólico produz sentidos e como o sujeito se constitui. Ao situar-se como lugar privilegiado de observação entre a língua, a ideologia e o sujeito, o discurso propicia, como bom observatório, a visualização das propriedades do complexo dispositivo teóricoanalítico (1996, p. 196).

As relações entre o sujeito e a ideologia são à base da construção da AD. Para compreender o discurso, não podemos esquecer a historicidade do enunciado, que leva o sujeito a crer que é o primeiro a enunciar. O sujeito, por sua vez, só produz discurso dentro de uma formação discursiva que está relacionada a uma formação ideológica remetida à 
"memória". Neste sentido, o discurso tem uma relação viva com a memória, portanto, sendo também alvo das manipulações sociais guiadas pelas políticas memoriais.

\subsection{Análise do discurso e a memória discursiva}

Escrever é tantas vezes lembrar-se do que nunca existiu. Como conseguirei saber do que nem ao menos sei? Assim: como se me lembrasse. Com um esforço de 'memória' como se eu nunca tivesse nascido. Nunca nasci, nunca vivi: mas eu me lembro e a lembrança é em carne viva (LISPECTOR, 1999, p. 385).

Esse ato de lembrar clamado na citação inicial é origem do discurso e das suas condições de produção relacionadas à Memória Discursiva. Para Achard (1999), a Memória Discursiva tenta construir uma "arqueologia" da Análise do Discurso, porque esta compõe-se de memórias socialmente criadas: a memória impõe desejos de materialidade. Neste sentido, a materialidade é implícita, pois ela espera uma compreensão, considerada comum, por ser óbvia para alguém. Segundo Pêcheux, "o acontecimento discursivo novo", "vem perturbar a memória", podendo "desmanchar a "regularização", porque o acontecimento desloca e desregula os implícitos associados ao sistema de regularização anterior”, podendo inaugurarse uma nova série de compreensões sobre determinado acontecimento histórico, já estabelecido no censo comum pela memória social (PÊCHEUX, 1999, p. 52). Assim, é necessário compreendermos que a Memória Discursiva pressupõe uma vulgata (censo comum oriundo de uma popularização de significado, que possuí regularidade) (ACHARD, 1999).

Portanto, a memória reconstrói-se a partir de lacunas, que são preenchidas pelo imaginário, interiorizado pelo sujeito, através das vivências forjadas nessa experiência do comum. Essas vivências assumem sentido de veracidade, mas não possuem possibilidade de serem remontadas de forma completa, já que têm relações diretas com o esquecimento. $\mathrm{O}$ discurso sobre o passado se estabelece fragmentado e com necessidades de completude, preso a consensos formulados e impostos aos sujeitos que compartilham do mesmo tempo e discurso, portanto, é forjado e moldado pela Memória Discursiva. Para Mutti:

na atividade de reconstituição do acontecimento pela memória, o sujeito mobiliza implícitos, sentidos pré-construídos que tendem a reforçar a regularização, pois surtem o efeito de já-lá; no entanto, se desestabilizam pelo sujeito que os resgata na sua enunciação,sempre única (2007, p. 266).

Assim, os discursos tendem a uma construção de sentido comum que se encontram e, ao mesmo tempo, chocam-se. Porém, nada é comum a todos, apenas os choques. Os choques e os contatos são vistos como regularidades fundantes do ato discursivo. 
modo reservatório: é necessariamente um espaço móvel de divisões, de disjunções, de deslocamento e de retomadas, de conflitos de regularização. Um espaço de desdobramentos, réplicas, polêmicas e contra-discursos. (PÊCHEUX, 1999, p. 56)

Não podemos esquecer que a Memória Discursiva deseja imagens e símbolos para prender-se. Segundo Achard (1999), a Memória Discursiva tem como desejo imagens - memórias que exprimem representações de sentido e significado. Assim, há uma regularidade de sentidos. A memória reconstrói-se através da verossimilhança. Nesses casos, a memória se estabelece através do enunciado e da enunciação que lhe dá um sentido de origem. Segundo Weinrich, “... nas línguas nada acontece sem a memória, nada, nada” (2006, p. 15). Mesmo que uma imagem retomada pelo discurso busque antigos significados, ela torna-se inelegível dentro do discurso, pois, quando a imagem é atravessada pelo discurso torna-se opaca e destoa mudando, perdendo valor de memória.

Nessa perspectiva, os modelos discursivos que se repetem seriam cópias ou inovações? Para Pêcheux, "a memória discursiva seria aquilo que, em face de um texto que surge como acontecimento a ler, vem restabelecer os 'implícitos' (quer dizer, mais tecnicamente, os pré-construídos, elementos citados e relatados, discursos transversos, etc.) de que sua leitura necessita: a condição do legível em relação ao próprio legível” (1999, p. 52). A Memória Discursiva transpõe sentidos presentes pelas ausências, estando sempre em jogo, sempre ativa e com sentidos deslizantes e mutáveis guiados pelo esquecimento. Assim, Pêcheux afirma que:

\footnotetext{
a memória como estruturação de materialidade discursiva complexa, estendida em uma dialética de repetição e regularização: a memória discursiva seria aquilo que, face, a um texto surge como acontecimento a ler, vem a restabelecer os 'implícitos' de que sua leitura necessita: a condição do legível em relação do legível (PÊCHEUX , 1999, p. 52).
}

Logo, para Pêcheux, a memória é móvel e inconstante. Por isso, a Memória Discursiva dentro do discurso assume duas funções, que operam de formas contrárias entre si, pois, se, por um lado, retoma o passado; por outro, elimina-o. Assim, formula-se a ideia de que os discursos não se apresentam prontos e nem acabados. É através da Memória Discursiva que os nossos saberes ganham sentido, mas esse sentido deve ser pensado como uma construção sócio-histórica datada e rememorada. "Para tratar do memorizável é preciso entender o acontecimento inscrito no espaço da memória sob dupla forma-limite: (1) o acontecimento que escapa à inscrição, que não chega a se inscrever; (2) o acontecimento que é absorvido na memória como se não tivesse acontecido" (PÊCHEUX, 1999, p. 52, p. 50). Ademais, Brandão afirma que 
a noção de memória discursiva separa e elege dentro de elementos constituídos numa determinada contingência histórica, aquilo que numa outra conjuntura dada, pode emergir atualizada, rejeitando o que não deve ser trazido à tona. Exercendo, dessa forma, uma função ambígua na medida em que recupera o passado e, ao mesmo tempo, o elimina com os apagamentos que opera, a memória irrompe na atualidade do acontecimento, produzindo determinados efeitos [...] (1999, p. 99).

Portanto, toda a Formação Discursiva está associada a uma memória discursiva, a qual constitui o intradiscurso da FD. Para Brandão, "enunciar é sempre se situar em relação a um já dito que se constitui no Outro no discurso" (1999, p. 96). Com isso, quando retiramos partes de outro discurso e formulamos um novo, estabelecemos novas condições de produção e novos discursos. A Memória Discursiva assume, como característica, a sua formulação em cascata, na qual fatos esquecidos sucedem-se de forma lacunar, construindo e formulando novos enunciados, a partir do sujeito. Conforme Orlandi, a Memória Discursiva é uma evocação do esquecimento como passado dentro do discurso (1999, p. 21). Logo, ela evoca a duplicidade da conjugação do conceito de memória que evoca o que foi esquecido, mas que se manteve em fragmento a ser rememorado.

Assim, o conceito de Memória Discursiva está ligado a uma recorrência de enunciações, na qual ocorrem escolhas e elas são eleitas por aquele que o "eu" rememora, dentro de uma necessidade histórica que é singular ao seu momento de rememoração. Tal discurso ao mesmo tempo em que forja uma Memória Discursiva, impõe o esquecimento de outro discurso. Portanto, atende a uma necessidade, mas pode ser renegado em uma nova posição discursiva, tal fenômeno abre espaço para a produção de um número ímpar de peculiaridades de efeitos e sentidos dentro do discurso. Ele é moldado pela necessidade da lembrança que deve vencer o esquecimento e estabelecer a Memória Discursiva.

Para Melo, “a noção de memória discursiva exerce, portanto, uma função ambígua no discurso, na medida em que recupera o passado e, ao mesmo tempo, o elimina com os apagamentos que opera" (1999, p. 100). Para Nietzsche, "somente por esquecimento, pode o homem alguma vez chegar a supor que possui alguma verdade” (1999, p. 55). Essa afirmação coloca o sujeito na falsa posição, na qual cada sujeito crê ser origem do discurso; essa crença faz com que o sujeito, que evoca a memória, veja-a como vivência sua e única.

Seguindo esse viés, a Memória Discursiva busca reconstruir enunciações, através de operações controladas que retomam sentidos e formas de difusão. Esses sentidos e formas de difusão impõem significados ao discurso que são retomados pelas relações de choque e convergência entre as memórias discursivas dos sujeitos, que enunciam o passado. O discurso só significa algo porque está inscrito e possui uma formação discursiva que é histórica e que não está presa aos desejos daquele que enuncia. 
O sujeito que enuncia tem a falsa impressão que o discurso é pronto, mas, ele sempre é incompleto. A Memória Discursiva carrega sentidos implícitos, que nem sempre estão presentes, mas ecoam no discurso. Segundo Ferreira:

A memória discursiva faz parte de um processo histórico resultante de uma disputa de interpretações para os acontecimentos presentes ou já ocorridos (Mariani, 1996). Coutine e Haroche (1994) afirmam que a linguagem e os processos discursivos são responsáveis por fazer emergir o que em uma memória coletiva, é característico de um determinado processo histórico. Orlandi (1993) diz que o sujeito toma como suas as palavras de uma voz anônima que se produz no interdiscurso, apropriando se da memória que se manifestará de diferentes formas em discursos distintos (2001, p. 20).

A Memória Discursiva faz-se importante para analisar o passado do discurso e seus sentidos mais subterrâneos que são evocados na sua enunciação. Para Brandão (1996), a Memória Discursiva está inserida dentro de um campo enunciativo, composto por vários campos de enunciação. Assim, o campo de presença é entendido como um conjunto de enunciados, no qual ocorre uma seleção em que alguns são escolhidos e outros são excluídos. Já o campo de concomitância é composto por enunciados, que são premissas que servem de generalizações para discursos divergentes. No domínio da memória, os enunciados não podem ser discutidos, pois, transpuseram-se em continuidades históricas do discurso que se filiam entre si.

Brandão (1996) afirma que as sequências discursivas compõem três domínios: de memória, da atualidade e de antecipação. Esses elementos, que formam os domínios, compõem referências datáveis e históricas do discurso. Para Brandão, "o domínio discursivo da memória é uma formação discursiva de referência" e seus efeitos podem ser de "lembranças, de redefinição, de transformação quanto ao esquecimento, de ruptura, de negação do já-dito" (1996, p. 99). Entretanto, o domínio de atualidade é fruto do efeito de memória retomado no presente, dessa maneira, discursos anteriores são retomados e reforçam discursos no presente. Para essa autora, o discurso de antecipação é formado por sequências discursivas formuladas no intradiscurso, que utilizam os efeitos do domínio da atualidade (BRANDÃO, 1996).

A formação discursiva, como Memória Discursiva, constrói-se com base na sua historicidade e esta relaciona-se com a interdiscursividade formada por memórias sociais constituintes de uma formação discursiva. Essas memórias sociais são constituintes da Memória Discursiva e são fruto dos Aparelhos Ideológicos de Estado, juntamente com o intradiscurso, são formadas pela atualidade do discurso e pelas suas relações com o presente. A Memória Discursiva se estabelece pela relação entre intradiscurso e interdiscurso, logo, essa dualidade relacional objetiva evocar um sentido de origem, no qual a repetição dos 
discursos fortalece a sua presença, porém, outra possibilidade encontra-se na memória fragmentada, que busca a construção do discurso pelo apagamento.

O conceito de Memória Discursiva reconstrói a História, que se inscreve pelo passado, que retorna ao discurso por vestígios, os quais remontam, dentro deste, os efeitos de memória. Para Orlandi, "a linguagem é linguagem porque faz sentido. E a linguagem só faz sentido por que se inscreve na história" (1999, p. 25). Logo, a sua historicidade só pode ser retomada a partir da Memória Discursiva e seus efeitos de memória. A Memória Discursiva, então, seria o gatilho do discurso, ela compõe o quadro dos sentidos que são objetivados por um discurso no momento da sua produção. Por ter características próprias frente ao discurso, a Memória Discursiva evoca o contexto de enunciação, que podemos entender com interdiscurso. Em conformidade com Orlandi, "o interdiscurso disponibiliza dizeres que afetam o modo como o sujeito significa em situação discursiva dada" (1999, p. 33). Ou seja, remete-se a um passado, que não está completo na situação do presente da enunciação. Contudo, o discurso remete a ele como uma possibilidade de sentido, que não é desejado objetivamente pelo sujeito, mas que se faz presente pelo não-dito no já-dito.

Os implícitos são destacados como memória no discurso e tornam-se presentes na formação discursiva. O consenso que se evoca pela rememorização está presente no discurso compreendido como representação concebida e percebida pelo sujeito. Segundo Achard,

\footnotetext{
[...] o implícito trabalha então sobre a base de um imaginário que o representa como memorizado, enquanto cada discurso, ao pressupô-lo, vai fazer apelo a (re) construção, sob a restrição 'no vazio' de que eles respeitem as formas que permitam sua inserção por paráfrase. Mas jamais podemos provar ou supor que esse implícito (re) construído tenha existido em algum lugar como discurso autônomo (1999, p. $13)$.
}

Essa impossibilidade de autonomia re-conecta o discurso ao passado, como legado que impõe sentido e significado ao discurso. Essa construção completa do conceito de Memória Discursiva foi elaborada no período final da obra teórica pecheutiana, como demonstra Zandwais (1999, p. 38). Portanto, o acontecimento passou a ser relacionado ao discurso, estipulando relações entre o espaço e o tempo. Nas páginas da sua obra "Discurso: Estrutura ou Acontecimento?", Pêcheux (2006) estabelece a relação entre o acontecimento e o momento histórico da sua enunciação. O conceito de Memória Discursiva analisad nessa obra relacionase com as formações ideológicas, que formam a materialidade discursiva, que remontam a um momento passado, que é (re)semantizado no presente pelo discurso em si. "Pêcheux acaba por demonstrar a impossibilidade de se pensar no funcionamento do discurso de ruptura sem que haja uma relação transversa entre a estrutura, a base linguística, o acontecimento, e os processos históricos através dos quais os acontecimentos se discursivizam" (ZANDWAIS, 1999, p. 42). O discurso não pode ser pensado sem memória, bem com a linguagem não pode 
ter significado sem a História, pois, como afirma Courtine (2006, p. 22), “a linguagem é o tecido da memória".

\section{Conclusão}

Para fecharmos este texto, que foi uma breve reflexão sobre as ligações da Análise Discursiva produzidas e construídas por Pêcheux, pensando a historicidade do discurso, optamos por retomar o conto de Jorge Luis Borges, "Funes, o Memorioso", usado na introdução deste artigo. Lembramos que o personagem do conto, Ireneo Funes, sofria com a incapacidade de esquecimento. Segundo Borges, Funes: "tinha aprendido sem esforço inglês, francês, português e latim. Suspeito, no entanto, de que não era muito capaz de pensar. Pensar é esquecer diferenças, é generalizar, abstrair” (BORGES, 2000, p. 80). Pensar e abstrair faz parte do ato discursivo, esquecer é primordial, para que o sujeito possa enquadrar-se dentro das diversas formações discursivas e que desliza pelas posições ideológicas que ele pode assumir.

O discurso compõe-se pela linguagem e toda a linguagem só significa porque pode ser historicizada. Todo o pensamento que leva á formulação do discurso só ocorre quando o esquecimento faz-se presente, pertencendo o esquecimento ao momento da enunciação. $\mathrm{O}$ esquecimento compõe a memória e oferta ao sujeito à falsa certeza de ser origem do discurso. O personagem Funes pode ser visto como fábula da construção hipertrofiada do discurso e do desejo do sujeito de ser fundador do discurso. Como lembra Borges, refletindo sobre os devaneios de Funes, que arquitetava a criação de uma língua que desse conta de nomear cada objeto com um nome próprio, impossibilitando a generalização e a interpretação (BORGES, 2000, p. 79).

Esse desejo formador da personalidade de Funes pode ser compreendido como a reconstrução baseada na repetição incessante de um enunciado, sem que o sujeito inscreva-se em uma formação ideológica, sem que o já-dito seja reconstruído na enunciação dos seus discursos, tendo em vista que todo o discurso de Funes é mera repetição, vazia, sem novos detalhes, sem esquecimento, sem interpretação, solidificado pela sua minuciosa capacidade de lembrar. Portanto, o presente artigo buscou compreender a relação do conceito de Memória Discursiva, para entender como esse conceito faz-se presente dentro do discurso, pois sem memória não há discurso.

\section{Referências}


ACHARD, Pierre. Memória e produção discursiva do sentido In: ACHARD, P. et al. (Org.) Papel da memória. Campinas: Pontes, 1999.

BRANDÃO, Helena H. Nagamine. Introdução à Análise do Discurso. Campinas, S. R: Editora da UN1CAMP, 1996.

COURTINE, J. O tecido da memória: algumas perspectivas de trabalho histórico nas ciências da linguagem. Polifonia, Cuiabá, edufmt v. 12 n. 2 p. 1-13, 2006.

BORGES, J. L. Ficções. Editorial Teorema, 2000.

FAIRCLOUGH, N. Discurso e mudança social. Brasília, Editora Universidade de Brasília, 2008.

FERREIRA, M. Glossário de termos do discurso. Porto Alegre: Instituto de Letras, UFRGS, 2001.

FERREIRA, Maria Cristina Leandro. O caráter singular da língua na Análise do Discurso. Organon 35, v. 17, n. 35, 2003.

HAROCHE, Claudine; HENRY, Paul; PÊCHEUX, Michel. [1971]. A Semântica e o corte saussuriano: língua, linguagem, discurso. In: BARONAS, R. L. Análise do Discurso: apontamentos para uma história da noção - conceito de formação discursiva. São Carlos: Pedro \& João Editores, 2007, pp. 13-32.

HENRY, P. Os fundamentos teóricos da análise automática do discurso de Michel Pêcheux. In: GADET, F. HAK, T. (Org.). Por uma análise automática do discurso: uma introdução à obra de Michel Pêcheux. Campinas: Ed. da UNICAMP, 1997. pp. 13-38.

LISPECTOR, C. A descoberta do mundo. Rio de Janeiro: Rocco, 1999.

PÊCHEUX, Michel. [1975]. Semântica e discurso: uma crítica à afirmação do óbvio. Campinas: Unicamp, 1988.

Editores, 2006.

O discurso: estrutura ou acontecimento. $4^{\text {a }}$ edição. Campinas, SP: Pontes

. Papel da memória. In: ACHARD, P. et al. (Org.) Papel da memória. Tradução e introdução José Horta Nunes. Campinas: Pontes, 1999.

[1969]. Análise automática do discurso (AAD-69). In: GADET, Françoise; HAK, Tony (orgs.). Por uma análise automática do discurso: uma introdução à obra de Michel Pêcheux. 2. ed. Campinas: Editora da Unicamp, 1997. pp. 61-161.

QUEIROZ, É. K. R. . (Re)lendo ad 69 hoje. In: I Seminário de Estudos em Análise do Discurso, 2003, Porto Alegre. I Seminário de Estudos em Análise do Discurso. Porto Alegre: Universitária, 2003.

MUTTI, R.M.V. Memória no discurso pedagógico. In: INDURSKY, F.; FERREIRA, M.C.L. (Orgs.). Análise do discurso no Brasil: mapeando conceitos, confrontando limites. São Carlos: Claraluz, 2007. pp. 265-76. 
MELO, C. (1999). Cartas à redação: uma abordagem discursiva. Tese de doutorado em linguística, Instituto de Estudos da Linguagem - IEL/Universidade de Campinas, 1999.

NARZETTI, C. As linhas de análise do discurso na frança nos anos 60-70. RevLet - Revista Virtual de Letras, Vol. 2, Número 02/2010, p.51-70, 2010.

NIETZSCHE, F. Coleção: Os Pensadores. São Paulo: Nova Cultura, 1999.

ORLANDI, E. Michel de Pêcheux e a Análise do Discurso. Revista Estudos de Linguagem, Vitória da Conquista, n 1, p. 9 -13, 2005.

. Análise de Discurso: princípios e procedimentos. Campinas: Pontes, 1999.

ZANDWAIS, Ana. Perspectivas da análise do discurso fundada por Michel Pêcheux na França: uma retomada de percurso. Santa Maria: UFSM, Programa de Pós-raduação em Letras, 2009. 